Bekkema, N., Veer, A.J.E. de, Wagemans, A.M.A., Hertogh, C.M.P.M., Francke, A.L. 'To move or not to move': a national survey among professionals on beliefs and considerations about the place of end-of-life care for people with intellectual disabilities. Journal of Intellectual Disability Research: 2015, 59(3), 226-237

\begin{tabular}{|l|l|}
$\begin{array}{l}\text { Postprint } \\
\text { Version }\end{array}$ & 1.0 \\
\hline Journal website & $\underline{\text { http://onlinelibrary.wiley.com/doi/10.1111/jir.12130/abstract }}$ \\
\hline Pubmed link & $\underline{\text { http://www.ncbi.nlm.nih.gov/pubmed/24861539 }}$ \\
\hline DOI & doi/10.1111/jir.12130/
\end{tabular}

\title{
'To move or not to move': a national survey among professionals on beliefs and considerations about the place of end-of-life care for people with intellectual disabilities
}

\author{
N. BekKema, A. J. E. De Veer, A. M. A Wagemans, C. M. P. M. Hertogh, A. L. Francke \\ NIVEL, Netherlands Institute of Health Services Research, Utrecht, The Netherlands \\ Koraalgroep, Maasveld, Maastricht, The Netherlands \\ Department of General Practice \& Elderly Care Medicine, EMGO Institute for Health and \\ Care Research, VU University Medical Center, Amsterdam, The Netherlands \\ Expertise Center for Palliative Care Amsterdam, VU University Medical Center, Amsterdam, \\ The Netherlands \\ Department of Public and Occupational Health, EMGO Institute for Health and Care \\ Research, VU University Medical Center, Amsterdam, The Netherlands
}

\begin{abstract}
Background: The aim of this article was to investigate the beliefs and considerations of professionals concerning an appropriate environment for endof-life care for people with intellectual disabilities (ID).

Method: A survey questionnaire was composed based on a scan of relevant literature and the results of group interviews with professionals, family members and people with ID. The questionnaire focused on the respondents' general beliefs about an appropriate environment for end-of-life care and their specific considerations regarding the place of care of the last client for whom the respondent provided end-of-life care. The questionnaire was sent to 294 care staff members recruited from a nationally representative panel of nurses and social workers, 273 ID physicians recruited from the members list of the Dutch professional association of ID physicians, and 1000 general practitioners (GPs) recruited from a nationally representative sample from a national registration of GPs.

Results: The overall response was $46 \%$. Professionals predominantly believe that all efforts should be made to ensure that a person with ID receives end-oflife care in their own home environment, and that 24/7 care is available. Respondents indicated that most of the clients (79\%) who had last received endof-life care from an ID care service were able to stay in their own home environment. Decisions to keep the client in their own home environment were
\end{abstract}


Bekkema, N., Veer, A.J.E. de, Wagemans, A.M.A., Hertogh, C.M.P.M., Francke, A.L. 'To move or not to move': a national survey among professionals on beliefs and considerations about the place of end-of-life care for people with intellectual disabilities. Journal of Intellectual Disability Research: 2015, 59(3), 226-237

primarily based on the familiarity of the environment and the expertise of the team in end-of-life care. Insufficient expertise and a lack of adequate equipment were the main considerations in decisions to move a client. Despite the belief of care staff in particular that the wishes of the person with ID should always be leading when deciding on the place of end-of-life care, only $8 \%$ of the care staff and ID physicians explicitly mentioned that the client's wishes were taken into account in actual decision-making.

Conclusions: Professionals agree that end-of-life care for people with ID should preferably take place in the client's home environment, even when nursing expertise, experience and adequate equipment are not (yet) in place. Nonetheless, a lack of expertise in end-of-life care is the foremost consideration in decisions to move a client. If ID care services want to promote end-of-life care in the client's own home, we recommend formulating a policy on how to realise end-of-life care in the client's own home environment and provide sufficient training and support for staff. To involve people with ID as much as possible, we recommend that professionals integrate more collaborative principles in decision-making about the place of end-of-life care.

\section{INTRODUCTION}

Most people prefer to remain in their own home environment up to the end of their life (Gomes et al. 2012; Fischer et al. 2013; Wilson et al. 2013). However, many people actually die in another place, such as a hospital or nursing home (Gomes \& Higginson 2008; Van der Velden et al. 2009). Transitions at the end of life can be related to several factors, such as multimorbidity, the availability of health care, a lack of social support or the patient's wishes (Cohen et al. 2006; Van den Block et al. 2007; Abarshi et al. 2010). It is thus far from certain people will receive end-of-life care (aimed at improving the quality of life of people with a life-threatening illness) in their own environment, whether patients in general or terminally ill people with an intellectual disability (ID). However, being cared for in a familiar surrounding may be even more important for people with ID.

Authors who argue in favour of end-of-life care in the client's own home environment point to the importance of familiarity and routine for people with ID (Kirkendall et al. 2012). Professionals in ID care services wish to care for their clients with ID themselves up to the very end (Todd 2004; McCarron et al. 2010a,b; Ryan et al. 2011; Wiese et al. 2012). However, several other studies show that staff working in ID care services often lack expertise and education in end-of-life care (Ng \& Li 2003; Botsford 2004; Stein 2008; McCarron et al. 2010a; Tuffrey-Wijne et al. 2010; Bekkema et al. 2014b). Ryan et al. (2010, 2011), for instance, found that Irish professionals caring for people with ID often lack confidence and training in end-oflife care, which led to considerable stress when they cared for terminally ill persons. In other care services, residential elderly care organisations or hospices, professionals may have more expertise and equipment to deliver high-quality end-oflife care. However, professionals working in such care services say that they have insufficient knowledge and communication skills to provide the specific attention that people with ID need (Todd 2005; Cartlidge \& Read 2010). Moreover, studies 
Bekkema, N., Veer, A.J.E. de, Wagemans, A.M.A., Hertogh, C.M.P.M., Francke, A.L. 'To move or not to move': a national survey among professionals on beliefs and considerations about the place of end-of-life care for people with intellectual disabilities. Journal of Intellectual Disability Research: 2015, 59(3), 226-237

reveal the difficulties that people with ID encounter when they move to general elderly care services, such as difficulties with participating in social activities and with building relationships with other residents (Thompson et al. 2004; Bigby et al. 2008).

This raises the question of what the best place is for providing end-of-life care for people with ID and what considerations professionals have regarding decisions about the place of care. Only one study specifically addressed the decision-making concerning the place of end-of-life care for people with ID: Tuffrey-Wijne (2009) found that although dying in their own home environment may be the ideal option for many people with ID, resources (e.g. the availability of personnel with relevant expertise and appropriate housing facilities) for supporting end-of-life care in the home environment were not always available. There have been other studies addressing decision-making about the place of care for ageing people with ID. These studies also found that arguments for moving a person to another setting were often related to limited resources for the care of aged clients in their own home environment (Janicki et al. 2002; Bigby et al. 2008). Moreover, Janicki et al. (2002) found that professionals' arguments that were used in decisions to keep an ageing person in their own home situation were often comparable with arguments used in decisions to move them to another setting. These studies suggest that resources (e.g. the expertise of professionals and housing facilities) may be important arguments in deciding upon the place of end-of-life care. Yet the considerations underlying decisions whether or not to move a person with ID to another care setting have only been loosely described so far.

Hence decision-making about the place of end-of-life care for people with ID remains unclear: where should end-of-life care be provided and why should it be provided there? To gain a broad insight, this study will examine both the general beliefs and the considerations in actual decision-making about the best place of endof-life care. Moreover, we will investigate whether different care professionals have distinct a priori beliefs about the best place of end-of-life care. The following research questions will be addressed:

1. To what extent do people receiving care from an ID care service move to another care setting to receive end-of-life care?

2. What considerations do the professionals concerned actually take into account when deciding on the place of end-of-life care for people with ID? Are decisions to provide end-of-life care in the client's own home environment based on different considerations compared with decisions to provide end-of-life care elsewhere?

3. What beliefs do professionals have with regard to an appropriate environment for end-of-life care for people with ID? Do care staff, ID physicians and general practitioners (GPs) differ in these beliefs?

\section{METHOD}

\section{Research subjects}

A pre-structured questionnaire was sent to three groups of professionals:

4. Care staff employed by care services for people with ID. The care staff were recruited from an existing nationally representative research panel of care professionals in the Netherlands (De Veer \& Francke 2010; De Veer et al. 
Bekkema, N., Veer, A.J.E. de, Wagemans, A.M.A., Hertogh, C.M.P.M., Francke, A.L. 'To move or not to move': a national survey among professionals on beliefs and considerations about the place of end-of-life care for people with intellectual disabilities. Journal of Intellectual Disability Research: 2015, 59(3), 226-237

2011). This research panel consists of a group of registered nurses (mainly associate or Bachelor's level), certified nursing assistants (associate level) and social workers (associate or Bachelor's level) who are prepared to fill in questionnaires on current topics in health care. Nurses generally receive more basic or post-basic vocational training in end-of-life care than social workers (Bekkema et al. 2014b). All registered nurses, certified nursing assistants and social workers who were members of the panel and who worked in ID care services (a total of 294 people) were sent a questionnaire.

5. ID physicians. ID physicians receive a 3-year specialist education in the care for people with ID. They are generally employed by an ID care service. All members of the Dutch professional association of ID physicians (a total of 273) were sent a questionnaire.

6. GPs. In the Netherlands, people with ID receive medical care from either an ID physician or a GP, with GPs commonly caring for people with mild ID living in the community. GPs were recruited by sending a questionnaire to a nationally representative sample of 1000 GPs, drawn from the national registration of about 9000 GPs in the Netherlands (Van Hassel \& Kenens 2013).

\section{Survey questionnaire}

The questionnaire focused on considerations and beliefs concerning an appropriate environment for end-of-life care for people with ID. The questions were based on a scan of relevant literature (e.g. Todd 2005; Cartlidge \& Read 2010; McCarron et al. 2010a,b; Tuffrey-Wijne et al. 2010), the results of two group interviews that were conducted with professionals $(\mathrm{n}=6)$ and family members $(\mathrm{n}=7)$, and two group interviews with people with mild or moderate ID $(n=10)$. Professionals and family members were interviewed about their considerations in decision-making concerning the place of end-of-life care, using the technique of moral case deliberation (Molewijk et al. 2008). People with ID were interviewed twice about the best place of end-of-life care using nominal group technique (Tuffrey-Wijne et al. 2007). The considerations that emerged from the literature and the group interviews were used to formulate the questions used in the survey questionnaire. The questionnaire was tested for comprehensibility and completeness among six ID physicians and six ID care staff members.

A specific part of the questionnaire addressed the place of care of the last client with ID for whom the respondent had provided end-of-life care. Respondents were asked where the client lived before the start of the illness, where end-of-life care was actually provided (using the response categories shown in Table 2) and what considerations were actually taken into account in deciding on the place of end-oflife care (open text field).

Beliefs about an appropriate environment for providing end-of-life care were measured by 11 statements that incorporated different aspects of the place and provision of end-of-life care (the response categories were 'strongly agree', 'agree', 'neutral', 'disagree' and 'strongly disagree'). 'Home' was defined as the original home situation of the person with ID, referring to all forms of accommodation (living independently, in a community group home or in a residential setting). Also, some questions were included on the respondent's background characteristics and workrelated characteristics. 
Bekkema, N., Veer, A.J.E. de, Wagemans, A.M.A., Hertogh, C.M.P.M., Francke, A.L. 'To move or not to move': a national survey among professionals on beliefs and considerations about the place of end-of-life care for people with intellectual disabilities. Journal of Intellectual Disability Research: 2015, 59(3), 226-237

For GPs, the questions on end-of-life care formed a part of a broader questionnaire on their experiences with patients with ID. GPs usually have only a few patients with ID in their practice (Straetmans et al. 2007) and will therefore have little or no experience with end-of-life care for people with ID. Therefore, GPs were not asked the specific questions about their last patient with ID who needed end-of-life care.

\section{Analysis}

In order to answer research question 1, crosstabs were calculated to measure the frequencies and percentages for the combination of original home situation before the start of the illness and the place where end-of-life care was actually provided. In order to answer research question 2, all considerations that were mentioned by the respondents were coded using a coding system that was developed on the basis of the prior scan of relevant literature and group interviews (see the 'questionnaire' section). Two authors (NB and AdV) coded the answers (Cohen's Kappa of 0.86 for inter-rater reliability). Fisher's exact tests were used to explore differences in considerations between decisions to provide end-of-life care in the client's own home environment and decisions to provide end-of-life care elsewhere.

In order to answer research question 3, the percentage selecting 'agree' or 'strongly agree', means and standard deviations (SD) for the belief questions were calculated to measure the beliefs of professionals concerning the provision of end-of-life care in the client's own home environment. ANCOVAs were performed to explore differences in beliefs between groups of professionals. The ANOCVAs included an adjustment for the possible influence of experience in end-of-life care and for the interaction between experience in end-of-life care and professional background. All analyses were performed using Stata 12.1.

\section{Ethical considerations}

The protocol for conducting the group interviews with people with ID (which were held to construct the survey questionnaire) was approved by the Medical Ethical Committee of the VU University Medical Center. The protocol for the questionnaire study and the group interviews with professionals and family members was in accordance with the Dutch Medical Research Involving Human Subjects Act (see ccmo-online.nl). All respondents received a letter informing them of the aim and goal of the study. Study participation was voluntary. The responses were anonymous and non-traceable to individuals.

\section{RESULTS}

\section{Background of the respondents}

A total of 718 questionnaires were completed. The overall response rate was $46 \%$. The response rate was $67 \%(n=196)$ for care staff, $53 \%(n=145)$ for ID physicians and $38 \%(\mathrm{n}=377)$ for GPs. The 196 care staff comprised 85 registered nurses, 8 certified nursing assistants and 103 social workers. The 377 responding GPs all had people with ID in their practice. However, reflecting the limited expertise GPs have with terminally ill people with ID, only 114 (30\% of the respondents) completed the questions on end-of-life care.

Table 1 shows that the responding ID physicians have on average less work experience as a professional (12.8 years) than the care staff (20.3 years) and GPs (18.6 years). ID physicians have more experience in providing end-of-life care for people with ID (94\%) than care staff (63\%). 
Bekkema, N., Veer, A.J.E. de, Wagemans, A.M.A., Hertogh, C.M.P.M., Francke, A.L. 'To move or not to move': a national survey among professionals on beliefs and considerations about the place of end-of-life care for people with intellectual disabilities. Journal of Intellectual Disability Research: 2015, 59(3), 226-237

[TABLE 1][TABLE 2]

\section{Moves to another care setting}

A total of 255 care staff and ID physicians responded to the questions about the last client with ID for whom they provided end-of-life care. Seventy-eight per cent of the clients concerned died less than 2 years ago. Table 2 shows that most lived in a residential setting or group home in the community. The table also shows that most (79\%) received end-of-life care in their original home environment. This was particularly the case for people who lived in a residential setting. The people who had their own apartment in the community or lived with family were least likely to receive end-of-life care in their original home environment. Most people who changed care settings moved to another department of the ID care service. Transitions to the home of a family member, a hospice or nursing home were less common. The three people who received end-of-life care in another setting all stayed in a hospital.

\section{Considerations in decisions about the place of end-of-life care}

The considerations underlying actual decisions about the place of end-of-life care were described for a total of 237 people (respondents' last client with ID for whom they provided end-of-life care). Table 3 shows that the top three considerations underlying decisions to provide end-of-life care in the client's own home environment were the client's familiarity with the environment (59\%), the team's expertise in end-of-life care (45\%) and the wishes/preferences of family members (16\%). The top three considerations underlying decision to move the client to another place were the team's lack of expertise in end-of-life care (57\%), the lack of equipment within the residence (28\%) and the unavailability of 24/7 care (17\%).

\section{[TABLE 3]}

We found several differences in how often different considerations were taken into account: the familiarity of the environment and the wishes/preferences of professionals were taken into account more often in decisions to provide end-of-life care in the client's own home environment than in decisions to provide end-of-life care elsewhere. The burden on the team, the number of professionals available, the availability to provide $24 / 7$ care and the equipment in the residence were taken into account more often in decisions to provide end-of-life care elsewhere than in decisions to provide end-of-life care in the client's own home environment.

\section{Beliefs concerning the provision of end-of-life care in the client's own home environment}

Table 4 shows that almost all professionals believe that every effort should be made to ensure that the client can stay in their own home environment (89\%) and that care should be offered $24 \mathrm{~h}$ a day, 7 days a week (82\%). Most respondents do not believe that a team without nursing experience cannot provide good end-of-life care.

Absence of experience in end-of-life is also not considered to be an obstacle to providing end-of-life care in the client's own home environment. The client's wishes are considered to be leading ( $72 \%$ ), but only $41 \%$ believe that this preference outweighs the quality of care that can be given at that place. Professionals generally do not believe that the equipment in a residence is an obstacle to the client staying in their own home environment, nor is the presence of other residents. 
Bekkema, N., Veer, A.J.E. de, Wagemans, A.M.A., Hertogh, C.M.P.M., Francke, A.L. 'To move or not to move': a national survey among professionals on beliefs and considerations about the place of end-of-life care for people with intellectual disabilities. Journal of Intellectual Disability Research: 2015, 59(3), 226-237

\section{[TABLE 4]}

Care staff are more likely than ID physicians and GPs to believe that the wishes of the client are always leading and they are more likely to stress the importance of 24/7 care. Fewer GPs than ID physicians believe that every effort should be made to ensure that the client can stay in their own home environment, and more GPs worry about the experience of professionals. GPs are also more likely than ID physicians and care staff to believe that professionals from other care organisations are able to care for seriously ill people with ID. ID physicians are least likely to believe that the presence of other residents is an obstacle to providing end-of-life care in a group home.

\section{DISCUSSION}

Most of the professionals in this study believed that every effort should be made to ensure that a person with ID can receive end-of-life care in their own home environment. In practice, most people (79\%) who received care from an ID care service in our study were able to remain in their own home environment, with the familiarity of the environment being the foremost consideration. This is a larger number than the figures we have from studies of the general population (Cohen et al. 2006; Van den Block et al. 2007; Van der Velden et al. 2009; Abarshi et al. 2010). Our study also revealed that although a lack of nursing expertise and adequate equipment is not generally believed to be an obstacle to providing end-of-life care in the client's own home environment, still the lack of expertise and equipment were the main considerations in decisions to move a client. This may explain why people living in their own apartment in the community or with family were more likely to be moved than people who lived in a residential setting. Despite the belief of care staff in particular that the wishes of the person with ID should always be leading in deciding on the place of care, only $8 \%$ of the care staff and ID physicians explicitly mentioned that the wishes of the client were taken into account in actual decisions.

\section{Familiarity and relationships}

Care staff and ID physicians said that staying in a familiar environment with care staff who know the person well and have known them for a long time provides that person with emotional security. This sense of security is important for people in the general population too. Yet it may be even more important for people with ID to be close to familiar caregivers, as it can be very difficult to 'read' their needs and identify signals such as distress and pain (Ryan et al. 2010; Bekkema et al. 2011). McCarron et al.'s study also demonstrated the importance of long-term relationships at the end of life, as for the staff in their study the maintenance of the relationship with the person with ID and dementia even outweighed the burden of the care on the team (McCarron et al. 2010a). Strong wishes of professionals to care for a client until the very end may also play a role. The wishes and preferences of professionals mentioned in our study were all in favour of keeping the client in their own home environment. Likewise, Wiese et al. (2012) found that staff were unanimous in their preference for end-of-life care at home where possible, including staff with negative past end-of-life care experiences.

As for relationships with other residents, their presence is not believed to be an obstacle to providing end-of-life care in the client's own home environment. 
Bekkema, N., Veer, A.J.E. de, Wagemans, A.M.A., Hertogh, C.M.P.M., Francke, A.L. 'To move or not to move': a national survey among professionals on beliefs and considerations about the place of end-of-life care for people with intellectual disabilities. Journal of Intellectual Disability Research: 2015, 59(3), 226-237

\section{Resources needed to provide end-of-life care}

A lack of expertise was the foremost consideration in decisions to move a client. This emphasises the need for continuing training in end-of-life care, particularly as an earlier study revealed that only $15 \%$ of care staff in ID care services feel adequately trained to provide good end-of-life care (Bekkema et al. 2014b). Nevertheless, professionals generally do not believe that a lack of nursing expertise or experience in end-of-life care is an obstacle to providing end-of-life care. This may be a reflection of the professionals' strong belief that the client should preferably stay in their own home environment. GPs (who work outside ID care services) are somewhat more critical; they worry more about a lack of experience and are more likely to believe that professionals from other care organisations are also able to care for seriously ill people with ID. On the other hand, expertise in end-of-life care was also an important consideration in decisions to keep the client in their own home environment. In these cases, the teams' expertise in end-of-life care may have been sufficient or supplemented sufficiently by the expertise of others, although the possibility of employing extra caregivers was not often mentioned as a consideration. Care staff in particular believe the availability of 24/7 care to be very important in determining where end-of-life care is provided. Indeed, the unavailability of 24/7 care was the third most common consideration in decisions to move a client. However, the availability of 24/7 care was rarely a consideration in decisions to keep a client in their own home environment. This may be explained by the fact that many of the clients in our study who stayed in their own home environment already lived in a residential setting, in which $24 / 7$ care may be seen as a natural part of care.

\section{Wishes of people with ID}

Being able to die according to your own preferences is generally found to be an important value in end-of-life care (Patrick et al. 2003). The majority of the professionals in our study (72\%) also believe that the wishes of the person with ID should always be leading in deciding on the place of end-of-life care. Care staff in particular (who work on a day-to-day basis with people with ID) seem in favour of giving the client's wishes considerable weight in decision-making. This is in line with the findings of Williams et al. (2010), who found that listening to the person with ID is central to the decision-making of ID nurses. Nonetheless, only $8 \%$ of the care staff and ID physicians explicitly mentioned that the wishes or preferences of the client were taken into account in actual decisions, while the wishes and preferences of family members were mentioned twice as often (15\%). It is unclear what this means. The difference may imply that decisions about the place of care are often driven in practice by professional and practical arguments, such as expertise and equipment, and that the wishes of the client can only be followed when they do not conflict with these professional and practical arguments. This would be in line with the belief that the client's preferences about where they want to spend the end of their life do not outweigh the quality of care that can be given at that place. It points to the responsibility of professionals to provide good-quality end-of-life care and confirms the weight given to resources as important considerations, which is in line with what has been found by Tuffrey-Wijne (2009). It may also be that the wishes of the person with ID were indeed taken into account in the actual decisions, but more implicitly, incorporated in other considerations such as the familiarity of the environment. It is also possible that the wishes were unclear, as it has been found that respecting the autonomy and eliciting the wishes of dying people with ID is very 
Bekkema, N., Veer, A.J.E. de, Wagemans, A.M.A., Hertogh, C.M.P.M., Francke, A.L. 'To move or not to move': a national survey among professionals on beliefs and considerations about the place of end-of-life care for people with intellectual disabilities. Journal of Intellectual Disability Research: 2015, 59(3), 226-237

difficult (Bekkema et al. 2014a). In that case, new ways to enhance the involvement of people with ID in decision-making need to be explored.

\section{Strengths and weaknesses}

An important strength of this study is that we studied both the considerations in actual decision-making and general beliefs. We were therefore able to provide a more profound insight into the decision-making on the place of end-of-life care for people with ID. Another strength is that we were able to recruit a broad group of professionals who work with people with ID by using two nationally representative samples and one members list that covers almost all practising Dutch ID physicians. A possible limitation of this study is the recall of the last client for whom care staff and ID physicians provided end-of-life care, although the majority of these clients died quite recently. Another limitation is that more than half of the actual decisions concerned people living in a residential setting, which may have resulted in an overrepresentation of people who were already receiving intensive care. Therefore, future studies should try to include a larger group of people who live in the community. Furthermore, future research should study the beliefs and considerations of relatives, as relatives are also part of the decision-making process. Finally, more knowledge is needed on how to enhance the involvement of people with ID in decision-making, as their wishes about the place of end-of-life care were rarely mentioned as a consideration in actual decisions.

\section{Recommendations}

According to professionals, end-of-life care for people with ID should preferably take place in their own home environment. In this regard, it is positive that most of the clients reported on actually seemed able to remain in their familiar environment. This study also indicates that the home environment needs to be able to provide adequate resources, such as personnel with expertise in end-of-life care, adequate equipment and 24/7 care, as a lack of such resources were the main considerations in decisions to move a client. If ID care services want to promote end-of-life care in the clients' own home, we therefore recommend that they (1) formulate a policy on how to realise end-of-life care in the client's own home environment; (2) encourage professionals to reflect on their own expertise and provide sufficient (continuing) training and expert consultation opportunities; and (3) provide emotional and practical support for staff. To enhance the involvement of people with ID in decision-making about the place of end-of-life care, professionals could learn from newly proposed models, such as the ASK ME model, that use collaborative principles to involve people with cognitive disabilities as much as possible in decision-making related to their care (Peisah et al. 2013).

\section{ACKNOWLEDGEMENTS}

The study was funded by ZonMw, the Netherlands Organization for Health Research and Development.

\section{REFERENCES}

Abarshi E., Echteld M. A., Van den Block L., Donker G., Deliens L. \& Onwuteaka-Philipsen B. (2010) Transitions between care settings at the end of life in the Netherlands: results from a nationwide study. Palliative Medicine 24, 166-174. 
Bekkema, N., Veer, A.J.E. de, Wagemans, A.M.A., Hertogh, C.M.P.M., Francke, A.L. 'To move or not to move': a national survey among professionals on beliefs and considerations about the place of end-of-life care for people with intellectual disabilities. Journal of Intellectual Disability Research: 2015, 59(3), 226-237

Bekkema N., Veer A. J. E., de Hertogh C. M. P. M. \& Francke A. L. (2011) Palliatieve Zorg voor Mensen met een Verstandelijke Beperking (Palliative care for People with Intellectual Disabilities). NIVEL, Utrecht.

Bekkema N., Veer A. J. E., de Hertogh C. M. P. M. \& Francke A. L. (2014a) Respecting autonomy in the end-of-life care of people with intellectual disabilities, a qualitative multiplecase study. Journal of Intellectual Disability Research 58, 368-380. doi: 10.1111/jir.12023

Bekkema N., Veer A. J. E., de Albers G., Hertogh C. M. P. M., Onwuteaka-Philipsen B. D. \& Francke A. L. (2014b) Training needs of nurses and social workers in the end-of-life care for people with intellectual disabilities: a national survey. Nurse Education Today 34, 494500. doi: 10.1016/j.nedt.2013.07.018

Bigby C., Webber R., McKenzie-Green B. \& Bowers B. (2008) A survey of people with intellectual disabilities living in residential aged care facilities in Victoria. Journal of Disability Research 52, 404-414.

Botsford A. L. (2004) Status of end of life care in organizations providing services for older people with a developmental disability. American Journal on Mental Retardation 109, 421428.

Cartlidge D. \& Read S. (2010) Exploring the needs of hospice staff supporting people with an intellectual disability: a UK perspective. International Journal of Palliative Nursing 16, 9398.

Cohen J., Bilsen J., Hooft P., Deboosere P., Wal G. \& Deliens L. (2006) Dying at home or in an institution using death certificates to explore the factors associated with place of death. Health Policy 78, 319-329.

De Veer A. J. \& Francke A. L. (2010) Attitudes of nursing staff towards electronic patient records: a questionnaire survey. International Journal of Nursing Studies 47, 846-854.

De Veer A. J., Fleuren M. A., Bekkema N. \& Francke A. L. (2011) Successful implementation of new technologies in nursing care: a questionnaire survey of nurse-users. BMC Medical Informatics and Decision Making 11, 67.

Fischer S., Min S. J., Cervantes L. \& Kutner J. (2013) Where do you want to spend your last days of life? Low concordance between preferred and actual site of death among hospitalized adults. Journal of Hospital Medicine 8, 178-183.

Gomes B. \& Higginson I. J. (2008) Where people die (1974-2030): past trends, future projections and implications of care. Palliative Medicine 22, 33-41.

Gomes B., Higginson I. J., Calanzani N., Cohen J., Deliens L., Daveson B. A. et al. on behalf of PRISMA (2012) Preferences for place of death if faced with advanced cancer: a population survey in England, Flanders, Italy, Germany, the Netherlands, Portugal and Spain. Annals of Oncology 23, 2006-2015.

Janicki M., McCallion P. \& Dalton A. (2002) Dementia-related care decision-making in group homes for persons with intellectual disabilities. Journal of Gerontological Social Work 38, 179-195.

Kirkendall A. M., Waldrop D. \& Moone R. P. (2012) Caring for people with intellectual disabilities and life-limiting illness: merging person-centered planning and patient-centered, family-focused care. Journal of Social Work in End-of-Life and Palliative Care 8, 135-150.

McCarron M., McCallion P., Fahey-McCarthy E. \& Connaire K. (2010a) Staff perceptions of essential prerequisites underpinning end-of-life care for persons with intellectual disability and advanced dementia. Journal of Policy and Practice in Intellectual Disabilities 7, 143152.

McCarron M., McCallion P., Fahey-McCarthy E., Connaire K. \& Dunn-Lane J. (2010b) Supporting persons with Down syndrome and advanced dementia. Dementia 9, 285-298.

Molewijk A. C., Abma T., Stolper M. \& Widdershoven G. (2008) Teaching ethics in the clinic. The theory and practice of moral case deliberation. Journal of Medical Ethics 34, 120-124.

$\mathrm{Ng}$ J. \& Li S. (2003) A survey exploring the educational needs of care practitioners in learning disability (LD) settings in relation to death, dying and people with learning disabilities. European Journal of Cancer Care 12, 12-19.

Patrick D. L., Curtis J. R., Engelberg R. A., Nielsen E. L. \& McCown E. B. (2003) Measuring and improving the quality of dying and death. Annals of Internal Medicine 139, 410-415.

Peisah C., Sorinmade O. A., Mitchell L. \& Hertogh C. M. P. M. (2013) Decisional capacity: toward an inclusionary approach. International Psychogeriatrics 25, 1571-1579. doi: 10.1017/S1041610213001014 
Bekkema, N., Veer, A.J.E. de, Wagemans, A.M.A., Hertogh, C.M.P.M., Francke, A.L. 'To move or not to move': a national survey among professionals on beliefs and considerations about the place of end-of-life care for people with intellectual disabilities. Journal of Intellectual Disability Research: 2015, 59(3), 226-237

Ryan K., McEvoy M., Guerin S. \& Dodd P. (2010) An exploration of the experience, confidence and attitudes of staff to the provision of palliative care to people with intellectual disabilities. Palliative Medicine 24, 566-572.

Ryan K., Guerin S., Dodd P. \& McEvoy J. (2011) End-of-life care for people with intellectual disabilities: paid carer perspectives. Journal of Applied Research in Intellectual Disabilities 24, 199-207.

Stein G. L. (2008) Providing palliative care to people with intellectual disabilities: services, staff knowledge, and challenges. Journal of Palliative Medicine 11, 1241-1248.

Straetmans J. M., van Schrojenstein-Lantman-de-Valk H. M., Schellevis F. G. \& Dinant G. J. (2007) Health problems of people with intellectual disabilities: the impact for general practice. British Journal of General Practice the Journal of the Royal College of General Practitioners 57, 64-66.

Thompson D., Ryrie I. \& Wright S. (2004) People with intellectual disabilities living in generic residential services for older people in the UK. Journal of Applied Research in Intellectual Disabilities 17, 101-108.

Todd S. (2004) Death counts: the challenge of death and dying in learning disability services. Learning Disability Practice 7, 12-15.

Todd S. (2005) Surprised endings: the dying of people with learning disabilities in residential services. International Journal of Palliative Nursing 11, 80-82.

Tuffrey-Wijne I. (2009) The preferred place of care for people who are dying. Learning Disability Practice 12, 16-21.

Tuffrey-Wijne I., Bernal J., Butler G., Hollins S. \& Curfs L. (2007) Using Nominal Group Technique to investigate the views of people with intellectual disabilities on end-of-life care provision. Journal of Advanced Nursing 58, 80-89.

Tuffrey-Wijne I., Bernal J. \& Hollins S. (2010) Disclosure and understanding of cancer diagnosis and prognosis for people with intellectual disabilities: findings from an ethnographic study. European Journal of Oncology Nursing 14, 224-230.

Van den Block L., Deschepper R., Drieskens K., Bauwens S., Bilsen J., Bossuyt N. et al. (2007) Hospitalizations at the end of life: using a sentinel surveillance network to study hospital use and associated patient, disease and healthcare factors. BMC Health Services Research 7, 69.

Van der Velden L. F. J., Francke A. L., Hingstman L. \& Willems D. (2009) Dying from cancer or other chronic diseases in the Netherlands: ten-year trends derived from death certificate data. BMC Palliative Care 8, 4.

Van Hassel D. T. P. \& Kenens R. J. (2013) Cijfers uit de Registratie van Huisarts: Peiling 2012 (Data from Registration of GPS: Measurements 2012). NIVEL, Utrecht.

Wiese M., Stancliffe R. J., Balandin S., Howarth G. \& Dew A. (2012) End-of-life care and dying: issues raised by staff supporting older people with intellectual disability in community living services. Journal of Applied Research in Intellectual Disabilities 25, 571-583.

Williams R. W., Roberts G. W., Irvine F. E. \& Hastings R. P. (2010) Exploring decision making in intellectual disability nursing practice: a qualitative study. Journal of Intellectual Disabilities 14, 197-220.

Wilson D. M., Cohen J., Deliens L., Hewitt J. A. \& Houttekier D. (2013) The preferred place of last days: results of a representative population-based public survey. Journal of Palliative Medicine 16, 502-508. doi: 10.1089/jpm.2012.0262

\section{TABLES}

\begin{tabular}{||l||l||l|l||c||}
\hline \multicolumn{5}{|c|}{ Table 1. Background characteristics of the respondents } \\
\hline \hline & $\begin{array}{l}\text { Total } \\
(\mathbf{n}=\mathbf{4 5 5})\end{array}$ & $\begin{array}{c}\text { Care staff } \\
(\boldsymbol{n}=\mathbf{1 9 6})\end{array}$ & $\begin{array}{c}\text { ID physicians } \\
(\boldsymbol{n}=\mathbf{1 4 5})\end{array}$ & $\begin{array}{c}\text { GPs } \\
(\boldsymbol{n}=\mathbf{1 1 4})\end{array}$ \\
\hline $\begin{array}{l}\text { Work experience as a } \\
\text { professional (years) }\end{array}$ & 17.4 & 20.3 & 12.8 & 18.6 \\
\hline
\end{tabular}


Bekkema, N., Veer, A.J.E. de, Wagemans, A.M.A., Hertogh, C.M.P.M., Francke, A.L. 'To move or not to move': a national survey among professionals on beliefs and considerations about the place of end-of-life care for people with intellectual disabilities. Journal of Intellectual Disability Research: 2015, 59(3), 226-237

\begin{tabular}{|l||c||c||c||c|}
\hline \multicolumn{6}{|c|}{ Table 1. Background characteristics of the respondents } \\
\hline \hline & $\begin{array}{c}\text { Total } \\
(\mathbf{n = 4 5 5 )}\end{array}$ & $\begin{array}{c}\text { Care staff } \\
(\mathbf{n = 1 9 6 )}\end{array}$ & $\begin{array}{c}\text { ID physicians } \\
(\mathbf{n}=\mathbf{1 4 5})\end{array}$ & $\begin{array}{c}\text { GPs } \\
(\boldsymbol{n}=\mathbf{1 1 4})\end{array}$ \\
\hline $\begin{array}{l}\text { Has experience in end-of-life } \\
\text { care for people with ID (\%) }\end{array}$ & 77.5 & 63.0 & 93.7 & n.a. \\
\hline
\end{tabular}

ID, intellectual disability; GPs, general practitioners

Table 2. Breakdown by place where end-of-life care was provided to the last client concerned, per original home situation (the situation before the onset of the illness), $n=255$ (table numbers are percentages)

\begin{tabular}{|c|c|c|c|c|c|c|c|}
\hline \multirow[b]{2}{*}{$\begin{array}{l}\text { Original home } \\
\text { situation }\end{array}$} & \multicolumn{7}{|c|}{ Place where end-of-life care was provided } \\
\hline & \begin{tabular}{|c|} 
In \\
original \\
home \\
situation \\
$(n=201)$ \\
\end{tabular} & \begin{tabular}{|c|} 
Other \\
department \\
of ID care \\
service \\
$(n=36)$ \\
\end{tabular} & $\begin{array}{c}\text { Family's } \\
\text { home } \\
(n=6)\end{array}$ & $\mid \begin{array}{c}\text { Hospice } \\
(n=5)\end{array}$ & $\begin{array}{l}\text { Nursing } \\
\text { home } \\
(n=4)\end{array}$ & $\begin{array}{l}\text { Other } \\
(n=3)\end{array}$ & $\begin{array}{c}\text { Total } \\
(n=255)\end{array}$ \\
\hline $\begin{array}{l}\text { Apartment or } \\
\text { group home in } \\
\text { a residential } \\
\text { setting } \\
(n=142)\end{array}$ & 88.0 & 10.6 & 0.7 & - & - & 0.7 & 100 \\
\hline $\begin{array}{l}\text { Group home in } \\
\text { the community } \\
(n=86)\end{array}$ & 68.6 & 20.9 & 3.5 & 2.3 & 3.5 & 1.2 & 100 \\
\hline $\begin{array}{l}\text { Own apartment } \\
\text { or home in the } \\
\text { community } \\
\text { (either living } \\
\text { independent or } \\
\text { with family) } \\
(n=18)\end{array}$ & 55.6 & 16.7 & 5.6 & 16.7 & - & 5.6 & 100 \\
\hline $\begin{array}{l}\text { Other/unknown } \\
(n=9)\end{array}$ & 77.8 & - & 11.1 & - & 11.1 & - & 100 \\
\hline Total $(n=255)$ & 78.8 & 14.1 & 2.4 & 2.0 & 1.6 & 1.2 & 100 \\
\hline
\end{tabular}

ID, intellectual disability

Table 3. Considerations that were taken into account in deciding upon the place of end-of-life (EOL) care (\% of respondents mentioning consideration)

\begin{tabular}{||l||c||c||c||}
\hline \hline & $\begin{array}{c}\text { Total } \\
(n=237)\end{array}$ & $\begin{array}{c}\text { EOL care in } \\
\text { own home } \\
\text { environment } \\
(\boldsymbol{n}=\mathbf{1 8 4})\end{array}$ & $\begin{array}{c}\text { EOL care } \\
\text { in another } \\
\text { place } \\
(\boldsymbol{n}=\mathbf{5 3})\end{array}$ \\
\hline Expertise in end-of-life care and continuity & & & \\
\hline
\end{tabular}


Bekkema, N., Veer, A.J.E. de, Wagemans, A.M.A., Hertogh, C.M.P.M., Francke, A.L. 'To move or not to move': a national survey among professionals on beliefs and considerations about the place of end-of-life care for people with intellectual disabilities. Journal of Intellectual Disability Research: 2015, 59(3), 226-237

Table 3. Considerations that were taken into account in deciding upon the place of end-of-life (EOL) care (\% of respondents mentioning consideration)

\begin{tabular}{|c|c|c|c|}
\hline & $\begin{array}{c}\text { Total } \\
(n=237)\end{array}$ & $\begin{array}{l}\text { EOL care in } \\
\text { own home } \\
\text { environment } \\
(n=184)\end{array}$ & \begin{tabular}{|c} 
EOL care \\
in another \\
place \\
$(n=53)$
\end{tabular} \\
\hline \multicolumn{4}{|l|}{ of care } \\
\hline $\begin{array}{l}\text { Expertise of the team in end-of-life care } \\
\text { (e.g. nursing skills and knowledge about } \\
\text { end-of-life care) }\end{array}$ & 47.7 & 45.1 & 56.6 \\
\hline \begin{tabular}{|l} 
Possibility to employ extra caregivers \\
(from inside or outside the own \\
organisation, e.g. nursing, behavioural or \\
palliative care experts, home care or \\
volunteers)
\end{tabular} & $\mid 11.8$ & 13.0 & ||7.6 \\
\hline $\begin{array}{l}\text { Burden on the team of professionals }{ }^{*}(e . g . \\
\text { the team's emotional stability and self- } \\
\text { confidence) }\end{array}$ & 6.8 & 4.4 & $\mid 15.1$ \\
\hline $\begin{array}{l}\text { Number of professionals } \\
\text { available/intensity of care needs }\end{array}$ & |5.1 & 2.7 & $\mid 13.2$ \\
\hline Availability of 24/7 care $^{* *}$ & 5.1 & 1.6 & 17.0 \\
\hline \multicolumn{4}{|l|}{ Familiarity } \\
\hline \begin{tabular}{|l|} 
Familiarity with the environment \\
the person with ID has lived for years in \\
the same setting, and been cared for by the \\
same care staff, which provides the person \\
with emotional security) \\
\end{tabular} & 46.4 & 59.2 & $\mid 1.9$ \\
\hline \multicolumn{4}{|l|}{ Equipment } \\
\hline \begin{tabular}{|l} 
Equipment within the residence (home \\
environment) ${ }^{*}$ (e.g. the possibility of \\
placing a bed downstairs, the presence of \\
patient lifters and available space for \\
medical supplies or a customised bed) \\
\end{tabular} & 16.5 & 13.0 & 28.3 \\
\hline \multicolumn{4}{|l|}{ Wishes/preferences } \\
\hline Wishes/preferences of family members & 15.2 & 15.8 & 13.2 \\
\hline Wishes/preferences of the person with ID & 8.4 & 9.8 & 3.8 \\
\hline Wishes/preferences of professionals $^{*}$ & 6.8 & 8.7 & 0.0 \\
\hline \multicolumn{4}{|l|}{ Other residents } \\
\hline \begin{tabular}{|l} 
Impact on other residents with ID (both \\
positive impact, e.g. supporting the ill \\
person and getting the opportunity to say \\
goodbye, and negative impact e.g. lack of \\
time for the care for other residents and \\
\end{tabular} & $\mid 5.1$ & 3.8 & $\mid 9.4$ \\
\hline
\end{tabular}


Bekkema, N., Veer, A.J.E. de, Wagemans, A.M.A., Hertogh, C.M.P.M., Francke, A.L. 'To move or not to move': a national survey among professionals on beliefs and considerations about the place of end-of-life care for people with intellectual disabilities. Journal of Intellectual Disability Research: 2015, 59(3), 226-237

Table 3. Considerations that were taken into account in deciding upon the place of end-of-life (EOL) care (\% of respondents mentioning consideration)

\begin{tabular}{|l||l|l|l||}
\hline \hline & $\begin{array}{c}\text { Total } \\
(\mathbf{n = 2 3 7})\end{array}$ & $\begin{array}{c}\text { EOL care in } \\
\text { own home } \\
\text { environment } \\
(\boldsymbol{n}=\mathbf{1 8 4})\end{array}$ & $\begin{array}{l}\text { EOL care } \\
\text { in another } \\
\text { place } \\
(\boldsymbol{n}=\mathbf{5 3})\end{array}$ \\
\hline \hline stress $)$ & & & \\
\hline \hline Other & & & 1.9 \\
\hline $\begin{array}{l}\text { Expected direct (emotional/physical) } \\
\text { burden of the (intended) move on the client }\end{array}$ & 5.9 & 7.1 & 0.0 \\
\hline \hline $\begin{array}{l}\text { Policy/vision of the ID care service } \\
\text { regarding the place of end-of-life care }\end{array}$ & 5.1 & 6.5 & 0.0 \\
\hline \hline Pace of deterioration of the client's health & 2.5 & 3.3 & 3.8 \\
\hline \hline Tranquillity of the home environment & 3.0 & 2.7 & 3.8 \\
\hline Other considerations & 3.0 & 2.7 & \\
\hline \hline
\end{tabular}

1. * Fisher exact test $=\mathrm{P}<0.01, * *$ Fisher exact test $=\mathrm{P}<0.05$.

2. Percentages do not add up to $100 \%$ as respondents could indicate multiple considerations per decision.

3. ID, intellectual disability.

Table 4. Beliefs regarding an appropriate environment for providing end-of-life care for people with ID

\begin{tabular}{|c|c|c|c|c|c|}
\hline & $\begin{array}{l}\text { \% Agree } \\
\text { or } \\
\text { strongly } \\
\text { agree } \\
\text { Total } \\
\end{array}$ & \begin{tabular}{|c} 
Mean \\
$($ SD) \\
Total $^{*}$
\end{tabular} & $\begin{array}{c}\text { Mean: } \\
\text { Care staff } \\
(n=192)\end{array}$ & $\begin{array}{c}\text { Mean: ID } \\
\text { physicians } \\
(n=143)\end{array}$ & $\begin{array}{l}\text { Mean: } \\
\text { GPs } \\
(n=114)\end{array}$ \\
\hline \multicolumn{6}{|l|}{ Expertise } \\
\hline $\begin{array}{l}\text { A team without nursing } \\
\text { expertise cannot provide } \\
\text { good end-of-life care. }\end{array}$ & 43.2 & $\mid \begin{array}{l}3.11 \\
(1.10)\end{array}$ & 3.18 & 2.94 & 3.21 \\
\hline $\begin{array}{l}\text { At the end of life, a client } \\
\text { should be housed somewhere } \\
\text { that can provide continuous } \\
\text { 24-hour care. }\end{array}$ & 82.4 & $\mid \begin{array}{l}3.96 \\
(0.79)\end{array}$ & 4.10 & 3.86 & 3.84 \\
\hline $\begin{array}{l}\text { If a team of care staff has no } \\
\text { prior experience in providing } \\
\text { end-of-life care, it would be } \\
\text { better for the client to move } \\
\text { elsewhere. }\end{array}$ & 5.9 & $\mid \begin{array}{l}2.30 \\
(0.69)\end{array}$ & 2.32 & 2.20 & 2.40 \\
\hline
\end{tabular}


Bekkema, N., Veer, A.J.E. de, Wagemans, A.M.A., Hertogh, C.M.P.M., Francke, A.L. 'To move or not to move': a national survey among professionals on beliefs and considerations about the place of end-of-life care for people with intellectual disabilities. Journal of Intellectual Disability Research: 2015, 59(3), 226-237

Table 4. Beliefs regarding an appropriate environment for providing end-of-life care for people with ID

\begin{tabular}{|c|c|c|c|c|c|}
\hline & $\begin{array}{c}\text { \% Agree } \\
\text { or } \\
\text { strongly } \\
\text { agree } \\
\text { Total } \\
\end{array}$ & \begin{tabular}{|c} 
Mean \\
(SD) \\
Total $^{*}$
\end{tabular} & $\begin{array}{c}\text { Mean: } \\
\text { Care staff } \\
(n=192)\end{array}$ & $\begin{array}{l}\text { Mean: ID } \\
\text { physicians } \\
(n=143)\end{array}$ & $\begin{array}{l}\text { Mean: } \\
\text { GPs } \\
(n=114)\end{array}$ \\
\hline \multicolumn{6}{|l|}{ Familiarity } \\
\hline \begin{tabular}{|l|} 
Every effort should be made \\
to enable the client to remain \\
in their own home \\
environment. ${ }^{\mathrm{c}}$
\end{tabular} & 88.9 & $\mid \begin{array}{l}4.16 \\
(0.67)\end{array}$ & 4.18 & 4.24 & 4.03 \\
\hline \begin{tabular}{|l|} 
Professionals in other \\
organisations (such as \\
hospices and nursing homes) \\
cannot provide the same \\
level of care for a seriously \\
ill client with an intellectual \\
disability as professionals in \\
intellectual disability care $_{\text {services. }}{ }^{\text {s }}$ \\
\end{tabular} & 44.2 & $\mid \begin{array}{l}3.23 \\
(0.94)\end{array}$ & 3.35 & 3.41 & 2.81 \\
\hline \multicolumn{6}{|l|}{ Equipment } \\
\hline $\begin{array}{l}\text { If a place is not fitted with } \\
\text { the appropriate equipment } \\
\text { and furnishings for the } \\
\text { provision of end-of-life care, } \\
\text { a client would be better off } \\
\text { moving to another place. } \\
\end{array}$ & 31.4 & $\begin{array}{l}2.9 \\
(0.90)\end{array}$ & 2.95 & 2.87 & 2.86 \\
\hline \multicolumn{6}{|l|}{ ID persons' wishes } \\
\hline $\begin{array}{l}\text { The client's wishes as to } \\
\text { where they want to live at the } \\
\text { end of life should always be } \\
\text { leading. }\end{array}$ & 72.2 & $\mid \begin{array}{l}3.83 \\
(0.84)\end{array}$ & 4.07 & 3.70 & 3.59 \\
\hline \begin{tabular}{|l|} 
A client's preferences \\
regarding where they wants \\
to live at the end of life \\
should be given greater \\
weight than the quality of the \\
care that can be provided in \\
that place.
\end{tabular} & 40.6 & $\mid \begin{array}{l}3.23 \\
(0.84)\end{array}$ & 3.43 & 3.09 & 3.06 \\
\hline \multicolumn{6}{|l|}{ Presence of other residents } \\
\hline \begin{tabular}{|l|} 
Care staff in a group home \\
who are providing end-of-life \\
care have insufficient time
\end{tabular} & 27.7 & $\mid \begin{array}{l}2.90 \\
(0.92)\end{array}$ & 3.05 & 2.62 & 2.99 \\
\hline
\end{tabular}


Bekkema, N., Veer, A.J.E. de, Wagemans, A.M.A., Hertogh, C.M.P.M., Francke, A.L. 'To move or not to move': a national survey among professionals on beliefs and considerations about the place of end-of-life care for people with intellectual disabilities. Journal of Intellectual Disability Research: 2015, 59(3), 226-237

Table 4. Beliefs regarding an appropriate environment for providing end-of-life care for people with ID

\begin{tabular}{|c|c|c|c|c|c|}
\hline & $\begin{array}{c}\text { \% Agree } \\
\text { or } \\
\text { strongly } \\
\text { agree } \\
\text { Total }\end{array}$ & $\begin{array}{l}\text { Mean } \\
\text { (SD) } \\
\text { Total }^{*}\end{array}$ & $\begin{array}{c}\text { Mean: } \\
\text { Care staff } \\
(n=192)\end{array}$ & $\begin{array}{c}\text { Mean: ID } \\
\text { physicians } \\
(n=143)\end{array}$ & $\begin{array}{c}\text { Mean: } \\
\text { GPs } \\
(n=114)\end{array}$ \\
\hline \multicolumn{6}{|l|}{$\begin{array}{l}\text { left for the care of the other } \\
\text { residents. }\end{array}$} \\
\hline $\begin{array}{l}\text { End-of-life care in a group } \\
\text { home is too disruptive for the } \\
\text { other residents. }{ }^{\text {g }}\end{array}$ & 8.9 & $\begin{array}{l}2.30 \\
(0.80)\end{array}$ & 2.46 & 2.03 & 2.36 \\
\hline $\begin{array}{l}\text { A group home is too } \\
\text { disruptive for a client who } \\
\text { receives end-of-life care. }\end{array}$ & 5.5 & $\begin{array}{l}2.32 \\
(0.72)\end{array}$ & 2.44 & 2.08 & 2.45 \\
\hline
\end{tabular}

$*$ Range $=1-5,1=$ strongly disagree $-5=$ strongly agree.

$P$ values reported for post-hoc Bonferroni test, after ANCOVA, $P<0.05$.

${ }^{a}$ Care staff vs. ID physicians: $\mathrm{p}=0.016$. Care staff vs. GPs: $P=0.015$.

${ }^{\mathrm{b}}$ ID physicians vs. GPs: $P=0.042$.

${ }^{\mathrm{c}}$ ID physicians vs. GPs: $P=0.037$.

${ }^{\mathrm{d}}$ Care staff vs. GPs: $P=0.000$. ID physicians vs. GPs: $P=0.000$.

${ }^{\mathrm{e}}$ Care staff vs. ID physicians: $P=0.000$. Care staff vs. GPs: $P=0.000$.

${ }^{\mathrm{f}}$ Care staff vs. ID physicians: $P=0.000$. ID physicians vs. GPs: $P=0.005$.

${ }^{\mathrm{g}}$ Care staff vs. ID physicians: $P=0.000$. ID physicians vs. GPs: $P=0.004$.

${ }^{\mathrm{h}}$ Care staff vs. ID physicians: $P=0.003$. ID physicians vs. GPs: $P=0.000$.

ID, intellectual disability; GPs, general practitioners. 